\title{
Pediatric Sepsis: Clinical Markers
}

\author{
$\begin{array}{llll}\text { S. Szima } & \text { G. Balazs } & & \text { N. Elek } \\ & & \text { P. Dahlem }\end{array}$ \\ ${ }^{1}$ Department of Pediatrics, Medical Center Coburg, Academic \\ Hospital of the University of Split, Coburg, Germany \\ 2 Institute of Pediatrics, Clinical Center, University of Debrecen, \\ Debrecen, Hungary
}

\begin{abstract}
Address for correspondence S. Szima, MD, Department of Pediatrics, Medical Center Coburg, Academic Hospital of the University of Split, Ketschendorfer Str. 33, 96450 Coburg, Germany

(e-mail: Sandor.Szima@Klinikum-Coburg.de).
\end{abstract}

J Child Sci 2017;7:e42-e53.

\begin{abstract}
Keywords
- sepsis
- physical examination
- evaluation
- septic shock
- children
- infection
- review
Pediatric sepsis can be caused by infection agents such as viruses, bacteria, protozoa, or their toxins. Clinical features cover a remarkably wide spectrum. Early recognition of the disease and prompt initiation of therapy substantially improve mortality and the outcome of potential complications. After an initial phase of very mild symptoms, the spread of microbes or toxins in the bloodstream presents as septic shock through vasoregulatory disturbance, absolute or relative intravascular volume loss, and consequential tachycardia and hypotension. The most common accompanying symptom is fever. In physical examination, features such as altered mental status, excess respiratory effort, tachycardia, and prolonged capillary refill time are present at an early stage of the disease. Laboratory tests for the assessment of early stage severity and subsequent monitoring of treatment efficacy include point-of-care arterial blood gas analysis and lactate assay. In early stage disease, it is imperative to promptly start adequate antimicrobial and supportive treatment once bacterial cultures have been taken. Despite the availability of a wide range of laboratory and imaging tests today, diagnosis and severity assessment of sepsis still primarily rely on medical history and clinical examination. In light of this, it is possible for trained care providers to detect the early signs of a septic child during repetitive physical examinations. This is still the mainstay of diagnosis and can provide in all care settings a significant reduction in therapeutic delay; this, in turn, helps to reduce sepsis-related mortality and morbidity.
\end{abstract}

\section{Introduction}

Pediatric sepsis is the most common, deadly disease in both the developing and developed world. Despite modern vaccines, antibiotics, and intensive care, the number of septic patients rises year after year. However, sepsis still continues to be the most frequently underdiagnosed entity. Timely and appropriately started therapy is highly cost-effective, whereas the 3 -day mortality of untreated cases is $100 \%$. In light of all this, our fundamental goal is the early diagnosis of sepsis. $^{1-4}$

Sepsis is a clinical syndrome resulting from a systemic inflammatory response (SIRS) evoked by severe infection. ${ }^{5}$ Physiological changes during SIRS are consequences of pathological immune-dysregulation leading to inflammation, microcirculatory disturbance, abnormal vasodilation or vasoconstriction, increased capillary permeability, and abnormal white blood cell accumulation. received

April 28, 2017

accepted after revision

April 30, 2017
Issue Theme Pediatric Sepsis Biomarkers; Guest Editors: Peter Dahlem, MD, PhD,

Marijan Saraga, MD, PhD,

Walter L. Strohmaier, MD, PhD

DOI https://doi.org/ 10.1055/s-0037-1603894. ISSN 2474-5871.
Copyright @ 2017 Georg Thieme Verlag KG Stuttgart · New York (c) 1 (icense terms $\$$ 
Although inflammation is vital in fighting against infections, the immune response during sepsis is abnormal, with the balance between pro- and anti-inflammatory mediators disrupted, culminating in damage to the body and multiple organ failure. ${ }^{6-12}$ Evidence exists that hereditary or acquired immune deficiency may particularly misdirect the immune response to pathogens, thus eliciting a more severe or more rapidly progressing clinical manifestation. ${ }^{10}$

Age, vaccination and immunological status, medical history, and chronic diseases may help to identify vulnerable patient groups. ${ }^{13-15}$

In establishing the diagnosis, the so-called systemic inflammatory response syndrome (SIRS) criteria are helpful. Of course, SIRS may also develop as a reaction evoked by other than pathogenic microorganisms. The confirmation of a noninfectious origin (e.g., trauma, burn, pancreatitis) may be useful in avoiding inadequate antibiotic therapy. However, confirmation of infection through microbiological (blood, liquor, stool, or urine culture, polymerase chain reaction $[\mathrm{PCR}]$ ) or radiological (chest X-ray) means should not delay initiation of adequate treatment (including prompt antimicrobial therapy). A delay in diagnosis and therapy significantly increases mortality. ${ }^{14-17}$ It is also important to assess initial mental status, respiratory function, intravascular volume status, and cardiac, hepatic, renal, hematological, and coagulation functions since these parameters may assist in finding the right level of therapy aggressiveness with the goal to improve significantly prognosis. ${ }^{18-21}$

\section{Diagnosis}

We must remember, however, that even though countless laboratory and imaging tests are available today, sepsis essentially remains a clinical diagnosis. Even consensus criteria for diagnosis of sepsis and septic shock may fail. Only two-third of patients treated at intensive care units for severe sepsis or septic shock satisfied the consensus criteria. ${ }^{22}$

The systemic inflammatory response syndrome, which was first introduced by the American College of Chest Physicians and the Society of Critical Care Medicine, helps us to detect the systemic inflammatory response, its severity, and the choice of therapy. ${ }^{23-25}$ In 2005, the International Pediatric Consensus Conference adapted the definition of SIRS, sepsis, and related diagnoses to age-specific normal values of childhood ( - Tables 1-4).

However, clinical presentation, physical examination findings, and laboratory test results are neither specific nor sensitive. Initial symptoms such as fever, cold chills, tachycardia and elevated respiratory rate are too general and often accompany merely a trivial viral infection. Prompt antibiotic therapy started in general upon these symptoms would only aggravate antibiotic resistance, a phenomenon already significantly observed worldwide. This may also cause unnecessary hospitalizations, with financial and social demands thereof. On the other hand, starting therapy only after occurrence of obvious clinical symptoms such as hemodynamic instability or altered mental status with impeding multiple organ failure unequivocally results in drastically elevated mortality.

Table 1 Definitions of SIRS, infection, sepsis, severe sepsis, and septic shock ${ }^{a}$

\begin{tabular}{|c|c|}
\hline \multirow[t]{5}{*}{$\mathrm{SIRS}^{\mathrm{a}, \mathrm{c}}$} & $\begin{array}{l}\text { The presence of at least two of the following four criteria, one of which must be abnormal } \\
\text { temperature or leukocyte count: }\end{array}$ \\
\hline & Core $^{\mathrm{b}}$ temperature of $>38.5^{\circ} \mathrm{C}$ or $<36^{\circ} \mathrm{C}$ \\
\hline & $\begin{array}{l}\text { Tachycardia, defined as a mean heart rate }>2 \text { SD above normal for age in the absence of external } \\
\text { stimulus, chronic drugs, or painful stimuli, or otherwise unexplained persistent elevation over a } \\
0.5 \text { - to } 4 \text {-h period or for children }<1 \text { y old: bradycardia, defined as a mean heart rate }<10 \text { th percentile } \\
\text { for age in the absence of external vagal stimulus, beta-blocker drugs, or congenital heart disease, or } \\
\text { otherwise unexplained persistent depression over a } 0.5 \text {-h time period }\end{array}$ \\
\hline & $\begin{array}{l}\text { Mean respiratory rate }>2 \text { SD above normal for age or mechanical ventilation for an acute process not } \\
\text { related to underlying neuromuscular disease or the receipt of general anesthesia }\end{array}$ \\
\hline & $\begin{array}{l}\text { Leukocyte count elevated or depressed for age (not secondary to chemotherapy-induced leukopenia) } \\
\text { or }>10 \% \text { immature neutrophils }\end{array}$ \\
\hline Infection & $\begin{array}{l}\text { A suspected or proven (by positive culture, tissue stain, or polymerase chain reaction test) infection } \\
\text { caused by any pathogen or a clinical syndrome associated with a high probability of infection. } \\
\text { Evidence of infection includes positive findings on clinical exam, imaging, or laboratory tests } \\
\text { (e.g., white blood cells in a normally sterile body fluid, perforated viscus, chest radiograph consistent } \\
\text { with pneumonia, petechial or purpuric rash, or purpura fulminans) }\end{array}$ \\
\hline Sepsis & SIRS in the presence of or as a result of suspected or proven infection \\
\hline Severe sepsis & $\begin{array}{l}\text { Sepsis plus one of the following: cardiovascular organ dysfunction or acute respiratory distress } \\
\text { syndrome or two or more other organ dysfunctions; organ dysfunctions are defined in } \mathbf{- T a b l e ~} 2\end{array}$ \\
\hline Septic shock & Sepsis and cardiovascular organ dysfunction as defined in - Table 2 \\
\hline
\end{tabular}

Abbreviations: SD, standard deviation; SIRS, systemic inflammatory response syndrome.

${ }^{a}$ Based on data from Goldstein et al. ${ }^{5}$

${ }^{\mathrm{b} C o r e}$ temperature must be measured by rectal, bladder, oral, or central catheter probe.

'See - Table 3 for age-specific ranges for physiological and laboratory variables. 
Table 2 Organ dysfunction criteria ${ }^{a}$

\begin{tabular}{|c|c|}
\hline \multirow[t]{10}{*}{ Cardiovascular dysfunction } & Despite administration of isotonic intravenous fluid bolus $\geq 40 \mathrm{~mL} / \mathrm{kg}$ in $1 \mathrm{~h}$ : \\
\hline & Decrease in BP (hypotension) 5th percentile for age or systolic BP $<2$ SD below normal for age \\
\hline & or \\
\hline & $\begin{array}{l}\text { Need for vasoactive drug to maintain BP in normal range (dopamine }>5 \mu \mathrm{g} / \mathrm{kg} / \mathrm{min} \text { or } \\
\text { dobutamine, epinephrine, or norepinephrine at any dose) }\end{array}$ \\
\hline & or two of the following: \\
\hline & Unexplained metabolic acidosis: base deficit $>5 \mathrm{mEq} / \mathrm{L}$ \\
\hline & Increased arterial lactate more than two times upper limit of normal \\
\hline & Oliguria: urine output $<0.5 \mathrm{~mL} / \mathrm{kg} / \mathrm{h}$ \\
\hline & Prolonged capillary refill: $>5 \mathrm{~s}$ \\
\hline & Core to peripheral temperature gap $>3^{\circ} \mathrm{C}$ \\
\hline \multirow[t]{7}{*}{ Respiratory } & $\mathrm{PaO}_{2} / \mathrm{FIO}_{2}<300$ in the absence of cyanotic heart disease or preexisting lung disease \\
\hline & or \\
\hline & $\mathrm{PaCO}_{2}>65$ Torr or $20 \mathrm{~mm} \mathrm{Hg}$ over baseline $\mathrm{PaCO}_{2}$ \\
\hline & or \\
\hline & Proven need or $>50 \% \mathrm{FiO}_{2}$ to maintain saturation $>92 \%$ \\
\hline & or \\
\hline & Need for nonelective invasive or noninvasive mechanical ventilation \\
\hline \multirow[t]{3}{*}{ Neurologic } & Glasgow Coma Score < 11 \\
\hline & or \\
\hline & $\begin{array}{l}\text { Acute change in mental status with a decrease in Glasgow Coma Score } \geq 3 \text { points from abnormal } \\
\text { baseline }\end{array}$ \\
\hline \multirow[t]{2}{*}{ Hematological } & $\begin{array}{l}\text { Platelet count of } 80,000 / \mathrm{mm}^{3} \text { or a decline of } 50 \% \text { in platelet count from highest value recorded } \\
\text { over the past } 3 \mathrm{~d} \text { (for chronic hematology/oncology patients) } \\
\text { or }\end{array}$ \\
\hline & International Normalized Ratio > 2 \\
\hline Renal & $\begin{array}{l}\text { Serum creatinine more than two times upper limit of normal for age or twofold increase in } \\
\text { baseline creatinine }\end{array}$ \\
\hline \multirow[t]{3}{*}{ Hepatic } & Total bilirubin < 4 mg/dL (not applicable for newborn) \\
\hline & or \\
\hline & ALT two times upper limit of normal for age \\
\hline
\end{tabular}

Abbreviations: ALT, alanine aminotransferase; BP, blood pressure; SD, standard deviation.

${ }^{a}$ Goldstein et al. ${ }^{5}$

Due to the severe nature of this clinical diagnosis and the potential for complications, all care providers should use a readily available, simple, rapidly and multiply repeatable, internationally accepted system of criteria with which disease progression and therapeutic efficacy could be monitored simply. Accepted in February 2016, the Third International Consensus Definitions for Sepsis and Septic Shock (Sepsis-3) are perfectly suitable for this. ${ }^{24}$

This article summarizes the most important objective clinical parameters, thus facilitating early recognition of sepsis.

\section{Body Temperature}

One of the key SIRS criteria is abnormal body temperature, be it hyperthermia or hypothermia. Fever is an adaptive response to infection. In vitro and animal experimental data confirm that cellular and humoral immunity shows increased antimicrobial activity when temperature is higher. ${ }^{25}$

In children, the most frequent clinical sign of a septic patient is a change in body temperature, mostly elevated core temperature. When assessing central body temperature, tympanic, rectal, urinary cystic, oral, or esophageal measurement sites can be used. Today, the tympanic temperature is most widely used during primary assessment.

Hypothermia is an independent prognostic factor in sepsis mortality assessment. Adult studies report an increased 90-day mortality when hypothermia develops during sepsis. One-fifth of septic patients are hypothermic at hospital admission. The mortality of these patients is twice as high, independent of age, disease severity, and concomitant diseases. ${ }^{26-28}$ Relevant studies have found no underlying etiological or unambiguously abnormal immunological 
Table 3 Pediatric age groups for severe sepsis definitions ${ }^{a}$

\begin{tabular}{|l|l|}
\hline Newborn & $0 \mathrm{~d}$ to $1 \mathrm{wk}$ \\
\hline Neonate & $1 \mathrm{wk}$ to $1 \mathrm{mo}$ \\
\hline Infant & $1 \mathrm{mo}$ to $1 \mathrm{y}$ \\
\hline Toddler and preschool & $2-5 \mathrm{y}$ \\
\hline School age child & $6-12 \mathrm{y}$ \\
\hline Adolescent and young adult & 13 to $<18 \mathrm{y}$ \\
\hline
\end{tabular}

${ }^{a}$ Goldstein et al. ${ }^{5}$

reasons. Elevated levels of fractalkine have been confirmed in hypothermia; it is a chemokine released upon endothelial cell damage with a possible role in the ensuing vascular dysfunction, but its clinical significance requires further research. ${ }^{26}$ Other studies on septic patients also reported increased mortality and hypothermia-associated lymphopenia, which is an early clinical predictor of sepsis-induced immunosuppression. ${ }^{29}$ Several studies reported on absolute leukocytopenia and lymphopenia in newborns receiving therapeutic hypothermia for hypoxic-ischemic encephalopathy. ${ }^{30}$

\section{Altered Mental Status}

An important part of early assessment is the evaluation of mental status. It is outstandingly important since it can be performed right upon contact with the patient, with no need for major physical, equipment-based or laboratory methods. It also lends itself to continuous, noninvasive monitoring of the mental status of the child.

In addition to the usual subjective description (irritability, nervousness, disorientation, lethargy, somnolence, stupor, coma), it can be continuously objectivized in real time using the internationally recognized Glasgow Coma Scale. Interestingly, in the emergency room, patients more frequently presented with an altered mental status (38.2\%) than with excess of respiratory effort (30.2\%). ${ }^{31}$ Clinical observations indicate that Glasgow Coma Scale scores of 11 or less and acute changes in mental status of at least two points are correlated with disease severity. Changes in mental status are affected by the general effects of inadequate tissue oxygenation in the body, insufficient tissue perfusion, potential hypoglycemia, and significant electrolyte disturbances. Of course, in septic events with an accompanying central nervous system infection (i.e., meningoencephalitis), local cerebral inflammation, circulation, and coagulation disturbances may also alter mental status.

\section{Respiratory System}

The examination and continuous monitoring of the respiratory system is indispensable when dealing with septic children. Strict observation and patency management of the airways is a key factor to ensure gas exchange. Rapid and objective assessment of the respiratory system is possible through tests such as age-specific respiratory rate, respiratory effort, auscultation, transcutaneous oxygen saturation, or blood gas analysis. Respiration rate is one of the most sensitive indicators of disease severity. ${ }^{32}$

Surprisingly, respiratory alkalosis of a central origin is often observable in early stage sepsis even before the onset of metabolic acidosis. As the disease progresses, the release of proinflammatory factors (cytokine storm) leads to a compromised lung compliance independent of age. In physical examination, nasal flaring, accessory respiratory muscle use, and appearance of suprasternal, subcostal, and sternal retractions may indicate, even before laboratory tests, the presence of acute lung injury (ALI) or the acute respiratory distress syndrome (ARDS), which are frequent complications confirmable by radiological (ultrasound, chest X-ray) and laboratory testing (arterial blood gas analysis). ${ }^{33}$ Peripheral circulatory failure developing as the process continues, coupled with the onset of metabolic acidosis as its consequence, causes the respiratory rate to increase further, now as a compensatory mechanism to maintain respiratory alkalosis.

This compensatory mechanism is dedicated to two possible reasons. A substantial number of septic cases have lower respiratory tract infection in the background, and gas exchange is compromised due to the primary involvement of the lungs. The most common cause of the aforementioned ALI or ARDS is sepsis. Locally released proinflammatory mediators are the underlying causes of

Table 4 Age-specific vital signs and laboratory variables ${ }^{a, b}$

\begin{tabular}{|c|c|c|c|c|c|}
\hline \multirow[b]{2}{*}{ Age group } & \multicolumn{2}{|c|}{ Heart rate (beats/min) } & \multirow{2}{*}{$\begin{array}{l}\text { Respiratory } \\
\text { rate (breaths/min) }\end{array}$} & \multirow{2}{*}{$\begin{array}{l}\text { Leukocyte count } \\
\text { (leukocytes } 10^{3} / \mathrm{mm}^{3} \text { ) }\end{array}$} & \multirow{2}{*}{$\begin{array}{l}\text { Systolic blood } \\
\text { pressure }(\mathrm{mm} \mathrm{Hg})\end{array}$} \\
\hline & Tachycardia & Bradycardia & & & \\
\hline $0 \mathrm{~d}$ to $1 \mathrm{wk}$ & $>180$ & $<100$ & $>50$ & $>34$ & $<65$ \\
\hline $1 \mathrm{wk}$ to $1 \mathrm{mo}$ & $>180$ & $<100$ & $>40$ & $>19.5$ or $<5$ & $<75$ \\
\hline $1 \mathrm{mo}$ to $1 \mathrm{y}$ & $>180$ & $<90$ & $>34$ & $>17.5$ or $<5$ & $<100$ \\
\hline $2-5 y$ & $>140$ & NA & $>22$ & $>15.5$ or $<6$ & $<94$ \\
\hline $6-12 y$ & $>130$ & NA & $>18$ & $>13.5$ or $<4.5$ & $<105$ \\
\hline 13 to $<18 y$ & $>110$ & NA & $>14$ & $>11$ or $<4.5$ & $<117$ \\
\hline
\end{tabular}

${ }^{\mathrm{a}}$ Goldstein et al. ${ }^{5}$

bower values for heart rate, leukocyte count, and systolic blood pressure are for the fifth and upper values for heart rate, respiration rate, or leukocyte count for the 95 th percentile. 
diffuse alveolar and pulmonary capillary injury, a process of exudative nature in the early phase. This results in an increased permeability of the alveolar-capillary barrier, upon which the alveoli get filled up with a protein-rich fluid. The process primarily affects type I pneumocytes. Type II, surfactant-producing cells are more resilient against the injury; however, damages to surfactant production lead to further deterioration of lung compliance and atelectasis. Neutrophils, tumor necrosis factor (TNF), various leukotrienes, macrophage inhibition factor, and other mediators released during sepsis have a substantial role in the process. The damaged alveolus collapses and is unable to refill with air at the next inspiration, thus escalating the ensuing atelectasis. This results in an early loss of functional residual capacity, an already limited resource in children, and, finally, global respiratory failure occurs. To compensate for the loss of lung compliance, accessory respiratory muscle effort is necessary by increasing respiration minute volume. ${ }^{34-44}$

The excessive respiratory effort may require up to $40 \%$ of the base metabolic rate and cardiac output. To avoid fatigue and consequential cardiorespiratory collapse in children, it is important to continuously monitor respiratory effort by physical examination and noninvasive transcutaneous saturation measurement, which is also informative of heart rate. Continuous observation helps determine when and how to start respiratory support, as well as facilitates close therapeutic efficacy monitoring once started. ${ }^{39,40,45-47}$

\section{Cardiovascular System}

Knowledge of age-specific heart rate, stroke volume, blood pressure, and systemic vascular resistance values, as well as their changes in response to the septic cascade triggered by infectious agents is indispensable for disease recognition and appropriate management. These are parameters with substantial differences between adults and various pediatric groups. ${ }^{41-43}$

Clinically informative assessment of the cardiovascular system also relies on a simultaneous evaluation of multiple parameters. During diagnosis and for rapid monitoring of therapeutic efficacy, key markers include the physical examination of heart rate and capillary refill time, and laboratory evaluation of arterial lactate levels and metabolic acidosis. Assessment of the cardiovascular system is assisted by noninvasive or invasive blood pressure measurement and continuous urinary output monitoring.

The triad triggered by inflammatory response, that is, fever, tachycardia, and altered vasoregulation, is a common set of symptoms in incipient pediatric infection. Suspicion of a septic event should be raised if these symptoms are accompanied by altered mental status, irritability, disorientation, and disturbed interpersonal contact. Similar to the respiratory system, the basis for the process is abnormal inflammation and dysregulation triggered and maintained by pathogens. The mechanisms leading to cell damage are not yet fully understood; however, postmortem data indicate a central role of endothelial damage in the evolution of the process.

Provoked by the injury, abnormal vascular tone, increased microvascular permeability, and leukocyte accumulation in- itially lead to relative and then absolute intravascular fluid deficit. Early symptoms of fluid deficit include an elevated heart rate and increased capillary refill time due to poor tissue perfusion. Owing to compensatory mechanisms, blood pressure drop is a late-onset symptom in most pediatric cases, together with reduced urinary output ( $<1 \mathrm{~mL} / \mathrm{kg} /$ hour $)$.

\section{Heart Rate}

Similar to respiratory rate, heart rate values are strongly age-specific. Changes in heart rate are a nonspecific sign, but it is a highly sensitive early stage indicator of relative or absolute fluid deficit, a common accompanying feature of pediatric shock; it is also one of the mechanisms to compensate for ongoing cardiac dysfunction or altered vascular resistance. $^{43}$

Heart rate variability (HRV) is an indicator of the heart's neurovegetative activity and autonomous function. It describes the heart's ability to continuously vary the time interval from heartbeat to heartbeat ( $R R$ interval) in response to changes in internal and external environmental demand; it is thus a measure of cardiac adaptability. Neither its etiology nor its exact clinical significance is clear yet; however, reduced HRV shows an association with poor outcomes in septic patients. HRV can predict the development of septic shock and multiple organ failure in sepsis. ${ }^{44,48-51}$ In newborns, it predicts blood culture positive septic cases independent of laboratory findings. ${ }^{52-54}$ An association is also detectable between hypercytokinemia, elevated interleukin (IL)-6, levels and reduced HRV in septic patients. ${ }^{55}$

Further research is needed to clarify the exact mechanisms of abnormal HRV and autonomous nervous system disorders. ${ }^{56-58}$

\section{Tissue Perfusion}

Microcirculation is the most important target in the septic process. Reduction in the number of functioning capillaries compromises oxygen utilization.

Several approaches exist to assess damaged microcirculation. The simplest, quickest, and most reproducible one is the measurement of capillary refill time. A capillary refill time of longer than 3 seconds is regarded as abnormal and prolonged.

Additional signs of disturbed microcirculation include altered skin temperature and skin color (paleness, mottling). Prolonged capillary refill time in incipient sepsis is a reliable indicator of vital organ microcirculation.

There are, of course, equipment-based tests available to assess the process. Spectrophotometry and sublingual/gastric assessment of orthogonal spectral polarization have not been established in daily routine diagnostics. ${ }^{59-63}$

Based on changes in hemodynamic response, cardiac output, and systemic vascular resistance, two forms of shock can be distinguished. ${ }^{64}$

Clinical manifestation may identify shock as being of the warm (hyperdynamic) type, characterized by low systemic vascular resistance, quick and prompt capillary refill time, warm skin all over the body, Corrigan's pulse, and wide pulse pressure (difference between systolic and diastolic blood pressure). 
Children's heart rates are physiologically higher than those of adults. So there is much less opportunity to further increase heart rate as a compensatory mechanism than in adults. Children therefore tend to raise their systemic vascular resistance in response to blood pressure decrease and to maintain it in the normal range.

In cold (hypodynamic) shock, systemic vascular resistance is high, the skin is cold and damp, a so-called coldwarm boundary can be detected, the capillary refill time is prolonged, the pulse is suppressible, and the pulse amplitude is narrow. There is, of course, a limit beyond which further vasoconstriction leads to a decrease in cardiac output, hypotension, circulatory failure, and eventually death, unless appropriate intervention is made. Earliest possible recognition and treatment of cold shock persisting in spite of normal blood pressures is therefore a key outcome factor. $^{65}$

Tissue perfusion, capillary refill time, and cold-warm boundary assessment are excellent markers in both shock severity evaluation and therapeutic efficacy monitoring. ${ }^{66-71}$

\section{Blood Pressure}

Blood pressure drop is a very late-phase manifestation in pediatric shock; therefore, normal age-specific blood pressure values early in the process do not help to exclude the diagnosis. They do help, however, differentiate between cold and warm shock in a noninvasive way. Treatment goals include restoring an age-specific normal blood pressure within the golden hour. Each hour spent outside the agespecific normal blood pressure range and with a capillary refill time of at least 3 seconds will double the mortality. ${ }^{72}$

Various hemodynamic values measured at emergency departments are characterized by various mortality estimates: normal heart rate, $1 \%$; tachycardia/bradycardia, $3 \%$; hypotension and capillary refill time $<3$ seconds, $5 \%$; normotension and prolonged capillary refill time, $7 \%$; hypotension and prolonged capillary refill time, 33\%. When hemodynamic values are normalized by treatment based on ACCM/PALS (American College of Critical Care Medicine-Pediatric Advanced Life Support) guidelines, a 40\% reduction in mortality can be observed, independent of the patient's group assignment at treatment initiation. ${ }^{40,73}$

\section{Subcutaneous Bleeding}

Skin changes, that is, color and temperature described previously, mainly depend on shock type. In either type, thrombocytopenia developing as part of the septic process causes petechiae, and an early physical symptom of disseminated intravascular coagulation is the appearance of purpura. All patients developing purpurae should be considered potentially severe cases. When suspecting invasive meningococcal infection, parenteral antibiotic treatment must be started immediately, even before arrival at the hospital.

Likewise, upon detection of grave thrombocytopenia, extensive, cause-finding examinations and coagulation tests must be performed.

Sepsis-induced disseminated intravascular coagulation may result in complement-mediated thrombotic microan- giopathy. The process may culminate in necrotizing fasciitis requiring a surgical solution. ${ }^{74-76}$

The most severe manifestation of the process is purpura fulminans, a life-threatening condition characterized by disseminated dermal and systemic thrombosis, skin bleeding and dermal necrosis, systemic microcirculation disorder, and multiple organ failure. The pathogenesis of the process is rooted in intrinsic coagulation cascade disorders and hereditary or acquired protein $C$ deficiency. ${ }^{77-80}$

\section{Laboratory Investigations}

Owing to the nature of the septic process, laboratory tests are run in parallel with treatment initiation while diagnosis is still being established. In full-blown septic shock, antimicrobial treatment and golden-hour therapy must not be delayed by laboratory tests (blood panel, inflammatory parameters, liver and kidney function tests).

\section{Microbiology}

Microbiological tests should take place before the onset of antimicrobial treatment, if possible, but must in no way cause significant delay (longer than 45 minutes).

It is recommended to collect an aerobic and an anaerobic blood culture sample from at least one sampling site, but preferably from two different sampling sites. ${ }^{81-85}$ From older children, volumes of 3 to $10 \mathrm{~mL}$ should be sampled, which reduces incidence of false-negative cases. ${ }^{86-96}$

In addition to conventional microbiological diagnosis, an alternative way of pathogen identification is PCR. Multiple PCR is well-known to deliver faster results, but requires a greater volume of blood, and is more prone to false-positive results and does not facilitate antibiogram assessment. ${ }^{96-102}$

\section{White Blood Cell Count}

Age-specific white blood cell count deviations and a percentage of immature forms higher than $10 \%$ are included in SIRS criteria as well. In suspicion of sepsis, the most fundamental laboratory test is total white blood cell count. Bacterial infection may entail both neutrophilia and neutropenia. The greater the proportion of immature white blood cells, the greater the chance of an infectious origin behind SIRS. ${ }^{103}$

\section{Inflammatory Markers}

Additional inflammatory markers recommended for use are sedimentation rate, C-reactive protein, IL-1b, IL-6, IL-8, TNF- $\alpha$, leukotriene B4, and procalcitonin (PCT). Because early disease symptoms are nonspecific, combined use of biomarkers is recommended for quick diagnostic judgment, rapid treatment initiation, and therapeutic efficacy monitoring, thereby significantly improving specificity and sensitivity. ${ }^{103-106}$

Inflammatory marker assessment is useful in predicting severe bacterial infection in infants and children with no clinically definite focal infectious lesions on hospital admission. ${ }^{107,108}$

In children aged 2 to 17 years, combined use of metabolic and inflammatory parameters helps identify patients who require intensive care. Information on multiple laboratory parameters is especially helpful in determining disease 
severity also in situations where care providers are less experienced in pediatric care. ${ }^{109}$

Patients who satisfy SIRS criteria and have elevated IL-6 levels are more likely to develop complications (pneumonia, multiple organ failure) and have a greater mortality risk. ${ }^{110}$ On the other hand, declining levels are a good indicator of therapeutic efficacy as early as day 2 of antibiotic treatment and have a positive predictive value in SIRS with an infectious origin. ${ }^{111}$

The soluble form of the CD14 cellular surface antigen is called presepsin (P-SEP). CD14 is a diagnostic and prognostic marker in adult sepsis. According to a prospective study, P-SEP in late-onset sepsis of premature babies is a potentially useful biomarker in both establishing diagnosis and treatment monitoring. ${ }^{105}$

Repeat assessment of markers with various half-lives helps confirm diagnosis and is suitable for disease activity monitoring; on a longer run, it also assists in judging the duration of antimicrobial therapy. PCT is more likely to help distinguish between viral and bacterial pathologies, but has a limited significance in determining the septic process in children as compared with adults..$^{103,106-121}$

\section{Platelet Count and Hemostasis}

Disseminated intravascular coagulation developing during sepsis is affected not only by basic coagulation factors but also by endothelial injury caused by thrombocytes and proinflammatory factors. Coagulation system assessment is imperative in critically ill patients. The most important tests include platelet count, partial thromboplastin time, international normalized ratio, and activated partial thromboplastin time.

In sepsis, thrombocytopenia is well correlated with disease severity and is an early predictor of poor outcomes. Of various other biomarkers, elevated levels of soluble thrombomodulin were associated with higher 90-day mortality and multiple organ failure.

Endothelial injury and consequential coagulopathy play a central role in sepsis pathogenesis and facilitate prognostic judgment. ${ }^{122-130}$

\section{Acid-Base Tests}

In critically ill patients, the most common bedside laboratory test is blood-gas analysis to assess acid-base homeostasis. If we define sepsis as a malignant intravascular inflammatory reaction, it is easy to see how an uncontrolled release of inflammatory mediators and complement activation lead to tissue oxygen deficit and consequential metabolic acidosis through increased oxygen consumption due to altered metabolic autoregulation and through reduced oxygen availability. ${ }^{131}$ The process is only aggravated by microcirculatory and endothelial dysfunction, and an initially relative, and later absolute, fluid deficit. Testing for $\mathrm{pH}$ and base deficit provides a quick and easy-to-represent picture of the body's metabolic status and therapeutic efficacy.

\section{Lactate}

Tissue lactate assessment is a good indicator of both appropriate tissue supply and aerobic glucose utilization. Elevated lactate levels are a good predictor of shock and tissue hypoperfusion even in normotensive patients. In suspicion of septic shock, it is recommended to test for lactate level at the time of diagnosis because it is known to be elevated in early stage shock. It is an excellent therapy monitoring marker; in the presence of elevated levels, therapeutic objectives include restoring a physiological lactate level. ${ }^{132-134}$

Pediatric evidence is limited, but one study has found that children satisfying SIRS criteria and having a venous lactate level greater than $4 \mathrm{mmol} / \mathrm{L}$ at diagnosis are more likely to develop organ dysfunction in the first 24 hours of treatment. ${ }^{135}$

\section{Blood Glucose}

Blood glucose testing is of fundamental importance in all critically ill children. Hypoglycemia, especially in infants, can be explained by altered metabolic utilization and a decline in enteral intake due to a poor general condition. Hypoglycemia, of course, needs immediate correction to avoid potential harmful neurologic outcomes. On the other hand, a disturbed glucose homeostasis, peripheral insulin resistance, and stress hormone release can lead to hyperglycemia as well. ${ }^{136,137}$ Stress-induced hyperglycemia has been reported in cases of meningococcemia. ${ }^{138,139}$

Both hypoglycemia and hyperglycemia have been reported to be associated with higher mortality in newborns. ${ }^{140}$ Since a correlation exists between hypercytokinemia and blood glucose levels in septic patients, adequate glycemic control is important during therapy. Under tight control, it is possible to avoid hypoglycemia induced by intensive insulin therapy. ${ }^{141-143}$

\section{Calcium}

Intracellular calcium has a major role in maintaining vascular tone and also affects myocardial function. Its assessment is important in any shock processes including septic shock. Reduced calcium levels are a frequent symptom in critically ill patients, most likely due to hormonal milieu alterations, but with a pathophysiology not yet fully understood. ${ }^{144-146}$ In sepsis, reduced calcium levels may contribute to a decreased myocardial function. ${ }^{147,148}$ Upon detecting a low ionized calcium level $(<1.1 \mathrm{mmol} / \mathrm{L})$ or symptomatic hypocalcemia (positive Chvostek or Trousseau sign, spasms, prolonged QT interval) during the septic process, immediate correction of the hypocalcemia is recommended. ${ }^{45,149}$

\section{Conclusion}

In summary, sepsis continues to play a significant role in childhood mortality today. In developed countries, a half of all premature and newborn mortality is originated from this disease. Sepsis mortality declines as children get older. Its significance is made even greater by a potential for serious long-term consequences in survivors due to tissue perfusion disturbance and subsequent multiple organ failure. Establishing the diagnosis of sepsis is not simple in any age. However, the nature of the process classifies it as what we call a time-factor disease, making sepsis diagnosis and treatment a real emergency task. Early recognition is the 
first step down the road toward reduced mortality rates. This requires continuous education of patients and their relatives to recognize early warning signs in vulnerable populations. Despite the availability of a wide range of laboratory, microbiological, and imaging tests today, sepsis continues to be a primarily clinical diagnosis. Medical history and a thorough physical examination are indispensable for diagnostic judgment. Owing to the dynamic nature of sepsis pathophysiology, evaluation and reevaluation of physical examination findings and bedside laboratory tests are indispensable not only in early diagnosis but also in controlling the therapeutic process. Most importantly, sepsis must be kept in mind as a potential diagnosis in almost every child in the emergency room when an infection cannot be excluded.

\section{References}

1 Angus DC, Linde-Zwirble WT, Lidicker J, Clermont G, Carcillo J, Pinsky MR. Epidemiology of severe sepsis in the United States: analysis of incidence, outcome, and associated costs of care. Crit Care Med 2001;29(07):1303-1310

2 Weiss SL, Fitzgerald JC, Pappachan J, et al; Sepsis Prevalence, Outcomes, and Therapies (SPROUT) Study Investigators and Pediatric Acute Lung Injury and Sepsis Investigators (PALISI) Network. Global epidemiology of pediatric severe sepsis: the sepsis prevalence, outcomes, and therapies study. Am J Respir Crit Care Med 2015;191(10):1147-1157

3 Odetola FO, Gebremariam A, Freed GL. Patient and hospital correlates of clinical outcomes and resource utilization in severe pediatric sepsis. Pediatrics 2007;119(03):487-494

4 Kissoon N, Carcillo JA, Espinosa V, et al; Global Sepsis Initiative Vanguard Center Contributors. World Federation of Pediatric Intensive Care and Critical Care Societies: Global Sepsis Initiative. Pediatr Crit Care Med 2011;12(05):494-503

5 Goldstein B, Giroir B, Randolph A; International Consensus Conference on Pediatric Sepsis. International pediatric sepsis consensus conference: definitions for sepsis and organ dysfunction in pediatrics. Pediatr Crit Care Med 2005;6(01):2-8

6 UpToDate. Systemic inflammatory response syndrome (SIRS) and sepsis in children: definitions, epidemiology, clinical manifestations, and diagnosis. Available at www.uptodate.com/contents/ systemic-inflammatory-response-syndrome-sirs-and-sepsis-inchildren-definitions-epidemiology-clinical-manifestations-anddiagnosis. Accessed March 11, 2017

7 Hotchkiss RS, Karl IE. The pathophysiology and treatment of sepsis. N Engl J Med 2003;348(02):138-150

8 Lederer JA, Rodrick ML, Mannick JA. The effects of injury on the adaptive immune response. Shock 1999;11(03):153-159

9 Payen D, Faivre V, Lukaszewicz AC, Villa F, Goldberg P. Expression of monocyte human leukocyte antigen-DR in relation with sepsis severity and plasma mediators. Minerva Anestesiol 2009;75(09):484-493

10 Hall MW, Knatz NL, Vetterly C, et al. Immunoparalysis and nosocomial infection in children with multiple organ dysfunction syndrome. Intensive Care Med 2011;37(03):525-532

11 Cinel I, Dellinger RP. Advances in pathogenesis and management of sepsis. Curr Opin Infect Dis 2007;20(04):345-352

12 Stearns-Kurosawa DJ, Osuchowski MF, Valentine C, Kurosawa S, Remick DG. The pathogenesis of sepsis. Annu Rev Pathol 2011; 6:19-48

13 Butt W. Septic shock. Pediatr Clin North Am 2001;48(03):601-625 , viii

14 Gaines NN, Patel B, Williams EA, Cruz AT. Etiologies of septic shock in a pediatric emergency department population. Pediatr Infect Dis J 2012;31(11):1203-1205
15 Kutko MC, Calarco MP, Flaherty MB, et al. Mortality rates in pediatric septic shock with and without multiple organ system failure. Pediatr Crit Care Med 2003;4(03):333-337

16 Wilkinson JD, Pollack MM, Glass NL, Kanter RK, Katz RW, Steinhart CM. Mortality associated with multiple organ system failure and sepsis in pediatric intensive care unit. J Pediatr 1987; 111(03):324-328

17 Leteurtre S, Martinot A, Duhamel A, et al. Validation of the paediatric logistic organ dysfunction (PELOD) score: prospective, observational, multicentre study. Lancet 2003;362(9379): 192-197

18 Graciano AL, Balko JA, Rahn DS, Ahmad N, Giroir BP. The Pediatric Multiple Organ Dysfunction Score (P-MODS): development and validation of an objective scale to measure the severity of multiple organ dysfunction in critically ill children. Crit Care Med 2005;33(07):1484-1491

19 Typpo KV, Petersen NJ, Hallman DM, Markovitz BP, Mariscalco MM. Day 1 multiple organ dysfunction syndrome is associated with poor functional outcome and mortality in the pediatric intensive care unit. Pediatr Crit Care Med 2009;10(05): 562-570

20 Weiss SL, Parker B, Bullock ME, et al. Defining pediatric sepsis by different criteria: discrepancies in populations and implications for clinical practice. Pediatr Crit Care Med 2012;13(04): e219-e226

21 Bone RC, Balk RA, Cerra FB, et al; The ACCP/SCCM Consensus Conference Committee. American College of Chest Physicians/ Society of Critical Care Medicine. Definitions for sepsis and organ failure and guidelines for the use of innovative therapies in sepsis. Chest 1992;101(06):1644-1655

22 Levy MM, Fink MP, Marshall JC, et al; International Sepsis Definitions Conference. 2001 SCCM/ESICM/ACCP/ATS/SIS International Sepsis Definitions Conference. Intensive Care Med 2003;29(04):530-538

23 Marshall JC. SIRS and MODS: what is their relevance to the science and practice of intensive care? Shock 2000;14(06): 586-589

24 Singer M, Deutschman CS, Seymour CW, et al. The Third International Consensus Definitions for Sepsis and Septic Shock (Sepsis-3). JAMA 2016;315(08):801-810

25 Launey Y, Nesseler N, Mallédant Y, Seguin P. Clinical review: fever in septic ICU patients-friend or foe? Crit Care 2011;15(03): 222. Doi: $10.1186 /$ cc 10097

26 Kushimoto S, Gando S, Saitoh D, et al; JAAM Sepsis Registry Study Group. The impact of body temperature abnormalities on the disease severity and outcome in patients with severe sepsis: an analysis from a multicenter, prospective survey of severe sepsis. Crit Care 2013;17(06):R271. Doi: 10.1186/cc13106

27 Tiruvoipati R, Ong K, Gangopadhyay H, Arora S, Carney I, Botha J. Hypothermia predicts mortality in critically ill elderly patients with sepsis. BMC Geriatr 2010;10:70. Doi: 10.1186/1471-2318$10-70$

28 Wiewel MA, Harmon MB, van Vught LA, et al. Risk factors, host response and outcome of hypothermic sepsis. Crit Care 2016; 20(01):328. Doi: 10.1186/s13054-016-1510-3

29 Drewry AM, Fuller BM, Skrupky LP, Hotchkiss RS. The presence of hypothermia within 24 hours of sepsis diagnosis predicts persistent lymphopenia. Crit Care Med 2015;43(06): 1165-1169

30 Jenkins DD, Lee T, Chiuzan C, et al. Altered circulating leukocytes and their chemokines in a clinical trial of therapeutic hypothermia for neonatal hypoxic ischemic encephalopathy. Pediatr Crit Care Med 2013;14(08):786-795

31 Wallgren UM, Bohm KEM, Kurland L. Presentations of adult septic patients in the prehospital setting as recorded by emergency medical services: a mixed methods analysis. Scand J Trauma Resusc Emerg Med 2017;25(01):23. Doi: 10.1186/ s13049-017-0367-z 
32 Kenzaka T, Okayama M, Kuroki S, et al. Importance of vital signs to the early diagnosis and severity of sepsis: association between vital signs and sequential organ failure assessment score in patients with sepsis. Intern Med 2012;51(08):871-876

33 Dahlem P, van Aalderen WM, Hamaker ME, Dijkgraaf MG, Bos AP. Incidence and short-term outcome of acute lung injury in mechanically ventilated children. Eur Respir J 2003;22(06):980-985

34 Ranieri VM, Rubenfeld GD, Thompson BT, et al; ARDS Definition Task Force. Acute respiratory distress syndrome: the Berlin Definition. JAMA 2012;307(23):2526-2533

35 Brierley J, Carcillo JA, Choong K, et al. Clinical practice parameters for hemodynamic support of pediatric and neonatal septic shock: 2007 update from the American College of Critical Care Medicine. Crit Care Med 2009;37(02):666-688

36 Santschi M, Jouvet P, Leclerc F, et al; PALIVE Investigators; Pediatric Acute Lung Injury and Sepsis Investigators Network (PALISI); European Society of Pediatric and Neonatal Intensive Care (ESPNIC). Acute lung injury in children: therapeutic practice and feasibility of international clinical trials. Pediatr Crit Care Med 2010;11(06):681-689

37 Randolph AG, Meert KL, O'Neil ME, et al; Pediatric Acute Lung Injury and Sepsis Investigators Network. The feasibility of conducting clinical trials in infants and children with acute respiratory failure. Am J Respir Crit Care Med 2003;167(10):1334-1340

38 Khilnani P, Singhi S, Lodha R, et al. Pediatric Sepsis Guidelines: summary for resource-limited countries. Indian J Crit Care Med 2010;14(01):41-52

39 Dellinger RP, Levy MM, Rhodes A, et al; Surviving Sepsis Campaign Guidelines Committee including the Pediatric Subgroup. Surviving sepsis campaign: international guidelines for management of severe sepsis and septic shock: 2012. Crit Care Med 2013;41(02):580-637

40 Wheeler DS, Wong HR, Zingarelli B. Pediatric sepsis - part I: "Children are not small adults!". Open Inflamm J 2011;4:4-15

41 Watson RS, Carcillo JA. Scope and epidemiology of pediatric sepsis. Pediatr Crit Care Med 2005;6(3, Suppl):S3-S5

42 Aneja R, Carcillo J. Differences between adult and pediatric septic shock. Minerva Anestesiol 2011;77(10):986-992

43 Parker MM, Shelhamer JH, Natanson C, Alling DW, Parrillo JE. Serial cardiovascular variables in survivors and nonsurvivors of human septic shock: heart rate as an early predictor of prognosis. Crit Care Med 1987;15(10):923-929

44 Chen WL, Kuo CD. Characteristics of heart rate variability can predict impending septic shock in emergency department patients with sepsis. Acad Emerg Med 2007;14(05):392-397

45 Pollack MM, Fields AI, Ruttimann UE. Sequential cardiopulmonary variables of infants and children in septic shock. Crit Care Med 1984;12(07):554-559

46 Kleinman ME, Chameides L, Schexnayder SM, et al. Part 14: pediatric advanced life support: 2010 American Heart Association Guidelines for Cardiopulmonary Resuscitation and Emergency Cardiovascular Care. Circulation 2010;122(18, Suppl 3): S876-S908

47 Randolph AG. Management of acute lung injury and acute respiratory distress syndrome in children. Crit Care Med 2009; 37(08):2448-2454

48 Pontet J, Contreras P, Curbelo A, et al. Heart rate variability as early marker of multiple organ dysfunction syndrome in septic patients. J Crit Care 2003;18(03):156-163

49 Chen WL, Chen JH, Huang CC, Kuo CD, Huang CI, Lee LS. Heart rate variability measures as predictors of in-hospital mortality in ED patients with sepsis. Am J Emerg Med 2008;26(04):395-401

50 Barnaby D, Ferrick K, Kaplan DT, Shah S, Bijur P, Gallagher EJ. Heart rate variability in emergency department patients with sepsis. Acad Emerg Med 2002;9(07):661-670

51 Ahmad S, Ramsay T, Huebsch L, et al. Continuous multi-parameter heart rate variability analysis heralds onset of sepsis in adults. PLoS One 2009;4(08):e6642. Doi: 10.1371/journal. pone. 0006642

52 Griffin MP, Lake DE, Moorman JR. Heart rate characteristics and laboratory tests in neonatal sepsis. Pediatrics 2005;115(04): 937-941

53 Cuestas E, Rizzotti A, Agüero G. Heart rate variability analysis: a new approach in clinical research methodology for neonatal sepsis [in Spanish]. Arch Argent Pediatr 2011;109(04): 333-338

54 Kovatchev BP, Farhy LS, Cao H, Griffin MP, Lake DE, Moorman JR. Sample asymmetry analysis of heart rate characteristics with application to neonatal sepsis and systemic inflammatory response syndrome. Pediatr Res 2003;54(06):892-898

55 Tateishi Y, Oda S, Nakamura M, et al. Depressed heart rate variability is associated with high IL-6 blood level and decline in the blood pressure in septic patients. Shock 2007;28(05): 549-553

56 Fairchild KD, O'Shea TM. Heart rate characteristics: physiomarkers for detection of late-onset neonatal sepsis. Clin Perinatol 2010;37(03):581-598

57 Fairchild KD. Predictive monitoring for early detection of sepsis in neonatal ICU patients. Curr Opin Pediatr 2013;25(02): 172-179

58 Scheff JD, Griffel B, Corbett SA, Calvano SE, Androulakis IP. On heart rate variability and autonomic activity in homeostasis and in systemic inflammation. Math Biosci 2014;252:36-44

59 Aird WC. The role of the endothelium in severe sepsis and multiple organ dysfunction syndrome. Blood 2003;101(10): 3765-3777

60 Astiz ME, DeGent GE, Lin RY, Rackow EC. Microvascular function and rheologic changes in hyperdynamic sepsis. Crit Care Med 1995;23(02):265-271

61 Neviere R, Mathieu D, Chagnon JL, Lebleu N, Millien JP, Wattel F. Skeletal muscle microvascular blood flow and oxygen transport in patients with severe sepsis. Am J Respir Crit Care Med 1996; 153(01):191-195

62 Temmesfeld-Wollbrück B, Szalay A, Mayer K, Olschewski H, Seeger W, Grimminger F. Abnormalities of gastric mucosal oxygenation in septic shock: partial responsiveness to dopexamine. Am J Respir Crit Care Med 1998;157(5 Pt 1):1586-1592

63 De Backer D, Creteur J, Preiser JC, Dubois MJ, Vincent JL. Microvascular blood flow is altered in patients with sepsis. Am J Respir Crit Care Med 2002;166(01):98-104

64 Ceneviva G, Paschall JA, Maffei F, Carcillo JA. Hemodynamic support in fluid-refractory pediatric septic shock. Pediatrics 1998;102(02):e19. Doi: 10.1542/peds.102.2.e19

65 Saavedra JM, Harris GD, Li S, Finberg L. Capillary refilling (skin turgor) in the assessment of dehydration. Am J Dis Child 1991; 145(03):296-298

66 Tibby SM, Hatherill M, Murdoch IA. Capillary refill and coreperipheral temperature gap as indicators of haemodynamic status in paediatric intensive care patients. Arch Dis Child 1999;80(02):163-166

67 Carcillo JA, Kuch BA, Han YY, et al. Mortality and functional morbidity after use of PALS/APLS by community physicians. Pediatrics 2009;124(02):500-508

68 Carcillo JA. Capillary refill time is a very useful clinical sign in early recognition and treatment of very sick children. Pediatr Crit Care Med 2012;13(02):210-212

69 Han YY, Carcillo JA, Dragotta MA, et al. Early reversal of pediatricneonatal septic shock by community physicians is associated with improved outcome. Pediatrics 2003;112(04):793-799

70 Pamba A, Maitland K. Capillary refill: prognostic value in Kenyan children. Arch Dis Child 2004;89(10):950-955

71 Fleming S, Gill P, Jones C, et al. Validity and reliability of measurement of capillary refill time in children: a systematic review. Arch Dis Child 2015;100(03):239-249 
72 Carcillo JA. Reducing the global burden of sepsis in infants and children: a clinical practice research agenda. Pediatr Crit Care Med 2005;6(3, Suppl):S157-S164

73 Abe T, Sasaki A, Ueda T, Miyakawa Y, Ochiai H. Complementmediated thrombotic microangiopathy secondary to sepsis-induced disseminated intravascular coagulation successfully treated with eculizumab: a case report. Medicine (Baltimore) 2017; 96(06):e6056. Doi: 10.1097/MD.0000000000006056

74 Ekeoduru RA, Greives MR, Nesrsta EA. Challenging airway secondary to purpura fulminans with face and neck bullae in a premature infant: a case report. A A Case Rep 2017;8(04):70-71

75 Brunkhorst FM, Patchev V. Sepsis-associated Purpura Fulminans International Registry-Europe (SAPFIRE) [in German]. Medizinische Klinik - Intensivmedizin und Notfallmedizin 2014; 109(08):591-595

76 Hale AJ, LaSalvia M, Kirby JE, Kimball A, Baden R. Fatal purpura fulminans and Waterhouse-Friderichsen syndrome from fulminant Streptococcus pneumoniae sepsis in an asplenic young adult. IDCases 2016;6:1-4

77 Wang Z, Yu Z, Su J, Cao L, Zhao X, Ruan C. Sepsis-induced disseminated intravascular coagulation with features of thrombotic thrombocytopenic purpura: a fatal fulminant syndrome. Clin Appl Thromb Hemost 2011;17(03):251-253

78 Flinn A, McDermott M, Butler KM. A child with septic shock and purpura. JAMA Pediatr 2016;170(04):391-392

79 Thomas AE, Baird SF, Anderson J. Purpuric and petechial rashes in adults and children: initial assessment. BMJ 2016;352:i1285. Doi: $10.1136 /$ bmj.i1285

80 Dr. Axel Bosk, Speyer (DSG, GNPI) Prof. Dr. Andreas Groll, Münster (Paul-Ehrlich-Gesellschaft für Chemotherapie e.V) PD Dr. Markus Hufnagel, Freiburg (DGPI), Prof. Dr. Thomas Lehrnbecher, Frankfurt (GPOH), Prof. Dr. Johannes Pöschl, Heidelberg (DGKJ, DIVI), Prof. Dr. Arne Simon, Homburg/Saar (DGPI), Prof. Dr. Constanze Wendt, Heidelberg Leitlinie Sepsis bei Kindern jenseits der Neonatalperiode AWMF-Register Nr. 024/025 Klasse: S2k

81 Struthers S, Underhill H, Albersheim S, Greenberg D, Dobson S. A comparison of two versus one blood culture in the diagnosis and treatment of coagulase-negative staphylococcus in the neonatal intensive care unit. J Perinatol 2002;22(07):547-549

82 Isaacman DJ, Karasic RB, Reynolds EA, Kost SI. Effect of number of blood cultures and volume of blood on detection of bacteremia in children. J Pediatr 1996;128(02):190-195

83 Kaditis AG, O'Marcaigh AS, Rhodes KH, Weaver AL, Henry NK. Yield of positive blood cultures in pediatric oncology patients by a new method of blood culture collection. Pediatr Infect Dis J 1996;15(07):615-620

84 Schelonka RL, Chai MK, Yoder BA, Hensley D, Brockett RM, Ascher DP. Volume of blood required to detect common neonatal pathogens. J Pediatr 1996;129(02):275-278

85 Kellogg JA, Manzella JP, Bankert DA. Frequency of low-level bacteremia in children from birth to fifteen years of age. J Clin Microbiol 2000;38(06):2181-2185

86 Buttery JP. Blood cultures in newborns and children: optimising an everyday test. Arch Dis Child Fetal Neonatal Ed 2002;87(01): F25-F28

87 Guerti K, Ieven M, Mahieu L. Diagnosis of catheter-related bloodstream infection in neonates: a study on the value of differential time to positivity of paired blood cultures. Pediatr Crit Care Med 2007;8(05):470-475

88 Tenney JH, Reller LB, Mirrett S, Wang WL, Weinstein MP. Controlled evaluation of the volume of blood cultured in detection of bacteremia and fungemia. J Clin Microbiol 1982; 15(04):558-561

89 Hall MM, Ilstrup DM, Washington JA II. Effect of volume of blood cultured on detection of bacteremia. J Clin Microbiol 1976;3(06): 643-645
90 Wagner SJ, Eder AF. A model to predict the improvement of automated blood culture bacterial detection by doubling platelet sample volume. Transfusion 2007;47(03):430-433

91 Kennaugh JK, Gregory WW, Powell KR, Hendley JO. The effect of dilution during culture on detection of low concentrations of bacteria in blood. Pediatr Infect Dis 1984;3(04):317-318

92 Auckenthaler R, Ilstrup DM, Washington JA II. Comparison of recovery of organisms from blood cultures diluted 10\% (volume/ volume) and 20\% (volume/volume). J Clin Microbiol 1982; 15(05):860-864

93 Solorzano-Santos F, Miranda-Novales MG, Leanos-Miranda B, Diaz-Ponce H, Palacios-Saucedo G. A blood micro-culture system for the diagnosis of bacteremia in pediatric patients. Scand J Infect Dis 1998;30(05):481-483

94 Zadroga R, Williams DN, Gottschall R, et al. Comparison of 2 blood culture media shows significant differences in bacterial recovery for patients on antimicrobial therapy. Clin Infect Dis 2013;56(06):790-797

95 Shahar E, Wohl-Gottesman BS, Shenkman L. Contamination of blood cultures during venepuncture: fact or myth? Postgrad Med J 1990;66(782):1053-1058

96 Lucignano B, Ranno S, Liesenfeld O, et al. Multiplex PCR allows rapid and accurate diagnosis of bloodstream infections in newborns and children with suspected sepsis. J Clin Microbiol 2011; 49(06):2252-2258

97 Dark P, Wilson C, Blackwood B, et al. Accuracy of LightCycler(R) SeptiFast for the detection and identification of pathogens in the blood of patients with suspected sepsis: a systematic review protocol. BMJ Open 2012;2(01):e000392

98 Dark P, Dunn G, Chadwick P, et al. The clinical diagnostic accuracy of rapid detection of healthcare-associated bloodstream infection in intensive care using multipathogen real-time PCR technology. BMJ Open 2011;1(01):e000181

99 Spencer DH, Sellenriek P, Burnham CA. Validation and implementation of the GeneXpert MRSA/SA blood culture assay in a pediatric setting. Am J Clin Pathol 2011;136(05):690-694

100 Tschiedel E, Steinmann J, Buer J, Felderhoff-Müser U, Rath PM, Dohna-Schwake C. Anwendung von LightCycler ${ }^{\circledR}$ SeptiFast bei pädiatrischen Patienten. Klinische Pädiatrie 2010;222

101 Tsalik EL, Jones D, Nicholson B, et al. Multiplex PCR to diagnose bloodstream infections in patients admitted from the emergency department with sepsis. J Clin Microbiol 2010;48(01): 26-33

102 Vincent JL, Beumier M. Diagnostic and prognostic markers in sepsis. Expert Rev Anti Infect Ther 2013;11(03):265-275

103 Reinhart K, Bauer M, Riedemann NC, Hartog CS. New approaches to sepsis: molecular diagnostics and biomarkers. Clin Microbiol Rev 2012;25(04):609-634

104 Nierhaus A, Klatte S, Linssen J, et al. Revisiting the white blood cell count: immature granulocytes count as a diagnostic marker to discriminate between SIRS and sepsis-a prospective, observational study. BMC Immunol 2013;14:8

105 Poggi C, Bianconi T, Gozzini E, Generoso M, Dani C. Presepsin for the detection of late-onset sepsis in preterm newborns. Pediatrics 2015;135(01):68-75

106 Mickiewicz B, Thompson GC, Blackwood J, et al; Alberta Sepsis Network. Development of metabolic and inflammatory mediator biomarker phenotyping for early diagnosis and triage of pediatric sepsis. Crit Care 2015;19:320

107 Luaces-Cubells C, Mintegi S, García-García JJ, et al. Procalcitonin to detect invasive bacterial infection in non-toxic-appearing infants with fever without apparent source in the emergency department. Pediatr Infect Dis J 2012;31(06):645-647

108 Maniaci V, Dauber A, Weiss S, Nylen E, Becker KL, Bachur R. Procalcitonin in young febrile infants for the detection of serious bacterial infections. Pediatrics 2008;122(04):701-710 
109 Lai CC, Chen SY, Wang CY, et al. Diagnostic value of procalcitonin for bacterial infection in elderly patients in the emergency department. J Am Geriatr Soc 2010;58(03):518-522

110 Jekarl DW, Lee SY, Lee J, et al. Procalcitonin as a diagnostic marker and IL-6 as a prognostic marker for sepsis. Diagn Microbiol Infect Dis 2013;75(04):342-347

111 Carcillo JA, Fields AI; American College of Critical Care Medicine Task Force Committee Members. Clinical practice parameters for hemodynamic support of pediatric and neonatal patients in septic shock. Crit Care Med 2002;30(06):1365-1378

112 Agyeman P, Aebi C, Hirt A, et al. Predicting bacteremia in children with cancer and fever in chemotherapy-induced neutropenia: results of the prospective multicenter SPOG 2003 FN study. Pediatr Infect Dis J 2011;30(07):e114-e119

113 Manzano S, Bailey B, Gervaix A, Cousineau J, Delvin E, Girodias JB. Markers for bacterial infection in children with fever without source. Arch Dis Child 2011;96(05):440-446

114 Fernández Lopez A, Luaces Cubells C, García García JJ, Fernández Pou J; Spanish Society of Pediatric Emergencies. Procalcitonin in pediatric emergency departments for the early diagnosis of invasive bacterial infections in febrile infants: results of a multicenter study and utility of a rapid qualitative test for this marker. Pediatr Infect Dis J 2003;22(10):895-903

115 Thayyil S, Shenoy M, Hamaluba M, Gupta A, Frater J, Verber IG. Is procalcitonin useful in early diagnosis of serious bacterial infections in children? Acta Paediatr 2005;94(02):155-158

116 Manzano S, Bailey B, Girodias JB, Galetto-Lacour A, Cousineau J, Delvin E. Impact of procalcitonin on the management of children aged 1 to 36 months presenting with fever without source: a randomized controlled trial. Am J Emerg Med 2010;28(06): 647-653

117 Enguix A, Rey C, Concha A, Medina A, Coto D, Diéguez MA. Comparison of procalcitonin with C-reactive protein and serum amyloid for the early diagnosis of bacterial sepsis in critically ill neonates and children. Intensive Care Med 2001;27(01):211-215

118 Pavcnik-Arnol M, Hojker S, Derganc M. Lipopolysaccharidebinding protein in critically ill neonates and children with suspected infection: comparison with procalcitonin, interleukin-6, and C-reactive protein. Intensive Care Med 2004;30(07): $1454-1460$

119 Rey C, Los Arcos M, Concha A, et al. Procalcitonin and C-reactive protein as markers of systemic inflammatory response syndrome severity in critically ill children. Intensive Care Med 2007;33(03):477-484

120 Arkader R, Troster EJ, Lopes MR, et al. Procalcitonin does discriminate between sepsis and systemic inflammatory response syndrome. Arch Dis Child 2006;91(02):117-120

121 Han YY, Doughty LA, Kofos D, Sasser H, Carcillo JA. Procalcitonin is persistently increased among children with poor outcome from bacterial sepsis. Pediatr Crit Care Med 2003;4(01):21-25

122 Levi M. Disseminated intravascular coagulation. Crit Care Med 2007;35(09):2191-2195

123 Bick RL. Disseminated intravascular coagulation current concepts of etiology, pathophysiology, diagnosis, and treatment. Hematol Oncol Clin North Am 2003;17(01):149-176

124 Barbui T, Falanga A. Disseminated intravascular coagulation in acute leukemia. Semin Thromb Hemost 2001;27(06):593-604

125 Williams MD, Chalmers EA, Gibson BE; Haemostasis and Thrombosis Task Force, British Committee for Standards in Haematology. The investigation and management of neonatal haemostasis and thrombosis. Br J Haematol 2002;119(02):295-309

126 Franchini M, Manzato F. Update on the treatment of disseminated intravascular coagulation. Hematology 2004;9(02):81-85

127 de Kleijn ED, de Groot R, Hack CE, et al. Activation of protein C following infusion of protein $C$ concentrate in children with severe meningococcal sepsis and purpura fulminans: a randomized, double-blinded, placebo-controlled, dose-finding study. Crit Care Med 2003;31(06):1839-1847
128 Veldman A, Fischer D, Wong FY, et al. Human protein C concentrate in the treatment of purpura fulminans: a retrospective analysis of safety and outcome in 94 pediatric patients. Crit Care 2010;14(04):R156

129 Ettingshausen CE, Veldmann A, Beeg T, Schneider W, Jäger G, Kreuz W. Replacement therapy with protein C concentrate in infants and adolescents with meningococcal sepsis and purpura fulminans. Semin Thromb Hemost 1999;25(06): 537-541

130 Johansen ME. Hemostasis and endothelial damage during sepsis. Dan Med J 2015;62(08):B5135

131 Pinsky MR, Matuschak GM. Multiple systems organ failure: failure of host defense homeostasis. Crit Care Clin 1989;5(02): 199-220

132 Dellinger RP, Carlet JM, Masur H, et al. Surviving Sepsis Campaign guidelines for management of severe sepsis and septic shock. Intensive Care Med 2004;30(04):536-555

133 Dellinger RP, Levy MM, Carlet JM, et al; International Surviving Sepsis Campaign Guidelines Committee; American Association of Critical-Care Nurses; American College of Chest Physicians; American College of Emergency Physicians; Canadian Critical Care Society; European Society of Clinical Microbiology and Infectious Diseases; European Society of Intensive Care Medicine; European Respiratory Society; International Sepsis Forum; Japanese Association for Acute Medicine; Japanese Society of Intensive Care Medicine; Society of Critical Care Medicine; Society of Hospital Medicine; Surgical Infection Society; World Federation of Societies of Intensive and Critical Care Medicine. Surviving Sepsis Campaign: international guidelines for management of severe sepsis and septic shock: 2008. Crit Care Med 2008;36(01):296-327

134 Scott HF, Donoghue AJ, Gaieski DF, Marchese RF, Mistry RD. The utility of early lactate testing in undifferentiated pediatric systemic inflammatory response syndrome. Acad Emerg Med 2012;19(11):1276-1280

135 McCowen KC, Malhotra A, Bistrian BR. Stress-induced hyperglycemia. Crit Care Clin 2001;17(01):107-124

136 Turina M, Fry DE, Polk HC Jr. Acute hyperglycemia and the innate immune system: clinical, cellular, and molecular aspects. Crit Care Med 2005;33(07):1624-1633

137 Day KM, Haub N, Betts H, Inwald DP. Hyperglycemia is associated with morbidity in critically ill children with meningococcal sepsis. Pediatr Crit Care Med 2008;9(06):636-640

138 van Waardenburg DA, Jansen TC, Vos GD, Buurman WA. Hyperglycemia in children with meningococcal sepsis and septic shock: the relation between plasma levels of insulin and inflammatory mediators. J Clin Endocrinol Metab 2006;91(10): 3916-3921

139 Ahmad S, Khalid R. Blood glucose levels in neonatal sepsis and probable sepsis and its association with mortality. J Coll Physicians Surg Pak 2012;22(01):15-18

140 Hirasawa H, Oda S, Nakamura M. Blood glucose control in patients with severe sepsis and septic shock. World J Gastroenterol 2009;15(33):4132-4136

141 Klein GW, Hojsak JM, Schmeidler J, Rapaport R. Hyperglycemia and outcome in the pediatric intensive care unit. J Pediatr 2008; 153(03):379-384

142 Branco RG, Garcia PC, Piva JP, Casartelli CH, Seibel V, Tasker RC. Glucose level and risk of mortality in pediatric septic shock. Pediatr Crit Care Med 2005;6(04):470-472

143 Sanchez GJ, Venkataraman PS, Pryor RW, Parker MK, Fry HD, Blick KE. Hypercalcitoninemia and hypocalcemia in acutely ill children: studies in serum calcium, blood ionized calcium, and calcium-regulating hormones. J Pediatr 1989;114(06): 952-956

144 Zaloga GP, Chernow B. The multifactorial basis for hypocalcemia during sepsis. Studies of the parathyroid hormone-vitamin D axis. Ann Intern Med 1987;107(01):36-41 
145 Müller B, Becker KL, Kränzlin M, et al. Disordered calcium homeostasis of sepsis: association with calcitonin precursors. Eur J Clin Invest 2000;30(09):823-831

146 Hobai IA, Edgecomb J, LaBarge K, Colucci WS. Dysregulation of intracellular calcium transporters in animal models of sepsis-induced cardiomyopathy. Shock 2015;43(01): 3-15

147 Kovacs A, Courtois MR, Barzilai B, Karl IE, Ludbrook PA, Hotchkiss RS. Reversal of hypocalcemia and decreased afterload in sepsis.
Effect on myocardial systolic and diastolic function. Am J Respir Crit Care Med 1998;158(06):1990-1998

148 Porcelli PJ Jr, Oh W. Effects of single dose calcium gluconate infusion in hypocalcemic preterm infants. Am J Perinatol 1995; 12(01):18-21

149 Forsythe RM, Wessel CB, Billiar TR, Angus DC, Rosengart MR. Parenteral calcium for intensive care unit patients. Cochrane Database Syst Rev 2008;(04):CD006163. Doi: 10.1002/ 14651858.CD006163.pub2 